\title{
Covered Stent Treatment of Carotid Blowout Syndrome
}

\author{
Ron C. Gaba, M.D., 1 Derek L. West, M.D., 1,2 James T. Bui, M.D., 1,2 \\ Charles A. Owens, M.D., ${ }^{1,2}$ and Franklin A. Marden, M.D. ${ }^{1,3}$
}

Carotid artery blowout is a devastating complication of head and neck malignancy, irradiation, and trauma. New endovascular therapies of acute carotid artery rupture involve stent-directed, carotid-sparing treatment strategies. We report a case of successful covered stent treatment of carotid artery hemorrhage in the setting of head and neck cancer and review the literature describing the use of this therapeutic method. Evaluation of 19 recently reported cases of covered stent treatment of carotid artery blowout due to head and neck cancer and presenting with sentinel or acute hemorrhage demonstrates that this method is a fast and effective means of controlling bleeding, with a technical success rate of $\sim 95 \%$. A significant early recurrent hemorrhage rate raises concern regarding the shortterm safety and efficacy of this therapy, however, and suggests that stent graft treatment of carotid artery rupture due to head and neck malignancy is best suited as a temporizing measure before more definitive therapy.

KEYWORDS: Carotid artery, blowout, stent

Objectives: Upon completion of this article, the reader should be able to (1) recognize the diagnostic features of carotid artery blowout, (2) describe possible endovascular treatment options for carotid artery rupture, (3) understand the current role of covered stent therapy for carotid artery blowout, and (4) review potential complications of covered stent treatment of carotid artery rupture.

Accreditation: Tufts University School of Medicine (TUSM) is accredited by the Accreditation Council for Continuing Medical Education to provide continuing medical education for physicians.

Credit: TUSM designates this educational activity for a maximum of 1 AMA PRA Category 1 Credit $^{\text {TM }}$. Physicians should only claim credit commensurate with the extent of their participation in the activity.

Rupture of the carotid artery, or so-called carotid blowout syndrome, is an uncommon but disastrous complication of head and neck cancer. Although carotid blowout occurs in up to $4.3 \%$ of patients with head and neck malignancy, ${ }^{1}$ it is associated with high rates of morbidity (60\%) and mortality (40\%). ${ }^{2}$ Endovascular therapies for carotid blowout syndrome have traditionally involved carotid artery sacrifice. More recently, stent-directed treatment methods, including the use of covered stents, have been employed to reduce the neurological morbidity associated with carotid artery occlusion. Although the use of stent grafts in the treatment of impending and acute carotid artery blowout is well known, a historical analysis of therapeutic outcomes of this procedure has not been presented. We describe a case of endovascular
${ }^{1}$ Department of Radiology, ${ }^{2}$ Section of Interventional Radiology, University of Illinois Medical Center at Chicago, Chicago, Illinois; ${ }^{3}$ Current affiliation: Fairfax Radiology, Fairfax, Virginia.

Address for correspondence and reprint requests: Ron C. Gaba, M.D., Department of Radiology, University of Illinois Medical Center at Chicago, 1740 West Taylor Street, MC 931, Chicago, IL 60612.
Case-Based Interventional Radiology; Guest Editors, Ron C. Gaba, M.D., Derek L. West, M.D., James T. Bui, M.D., Charles A. Owens, M.D.

Semin Intervent Radiol 2007;24:47-52. Copyright (C) 2007 by Thieme Medical Publishers, Inc., 333 Seventh Avenue, New York, NY 10001, USA. Tel: +1(212) 584-4662.

DOI 10.1055/s-2007-971189. ISSN 0739-9529. 
treatment of carotid blowout syndrome utilizing a covered stent and review the recent literature describing this treatment method, with particular attention to the technical success, complications, and long-term efficacy.
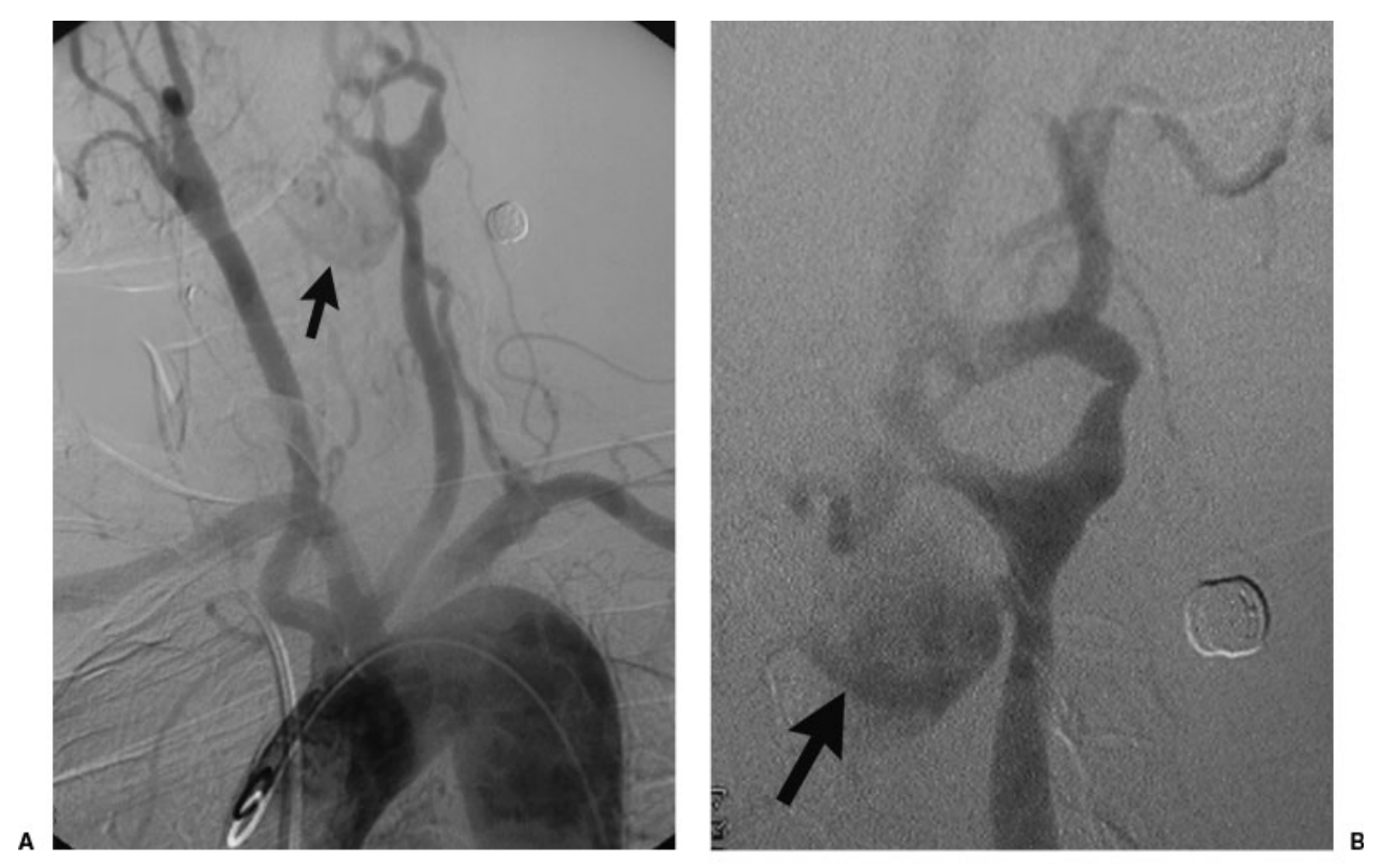

\section{CASE REPORT}

A 60-year-old man was transferred to our institution for definitive management of a giant left carotid artery pseudoaneurysm. The patient had previously undergone partial laryngectomy and chemoradiation therapy for

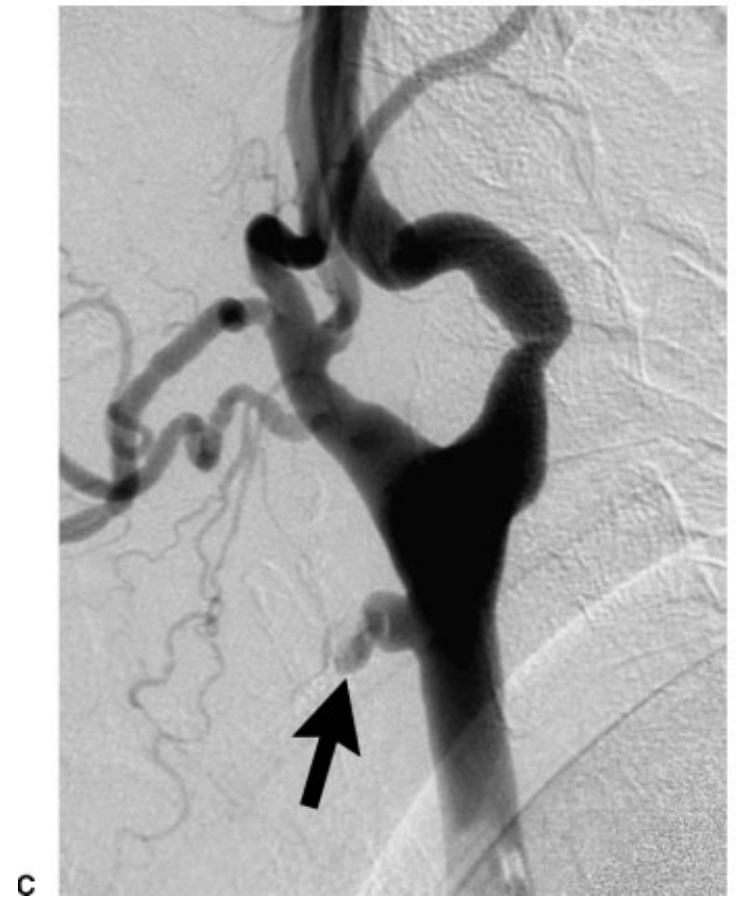

Figure 1 60-year-old man with acute carotid blowout syndrome. (A) Aortogram and (B) left carotid arteriogram reveal 3-cm pseudoaneurysm (arrow) arising from medial aspect of distal left common carotid artery. (C) Left carotid arteriogram obtained 21 hours later shows persistent filling of pseudoaneurysm base. 

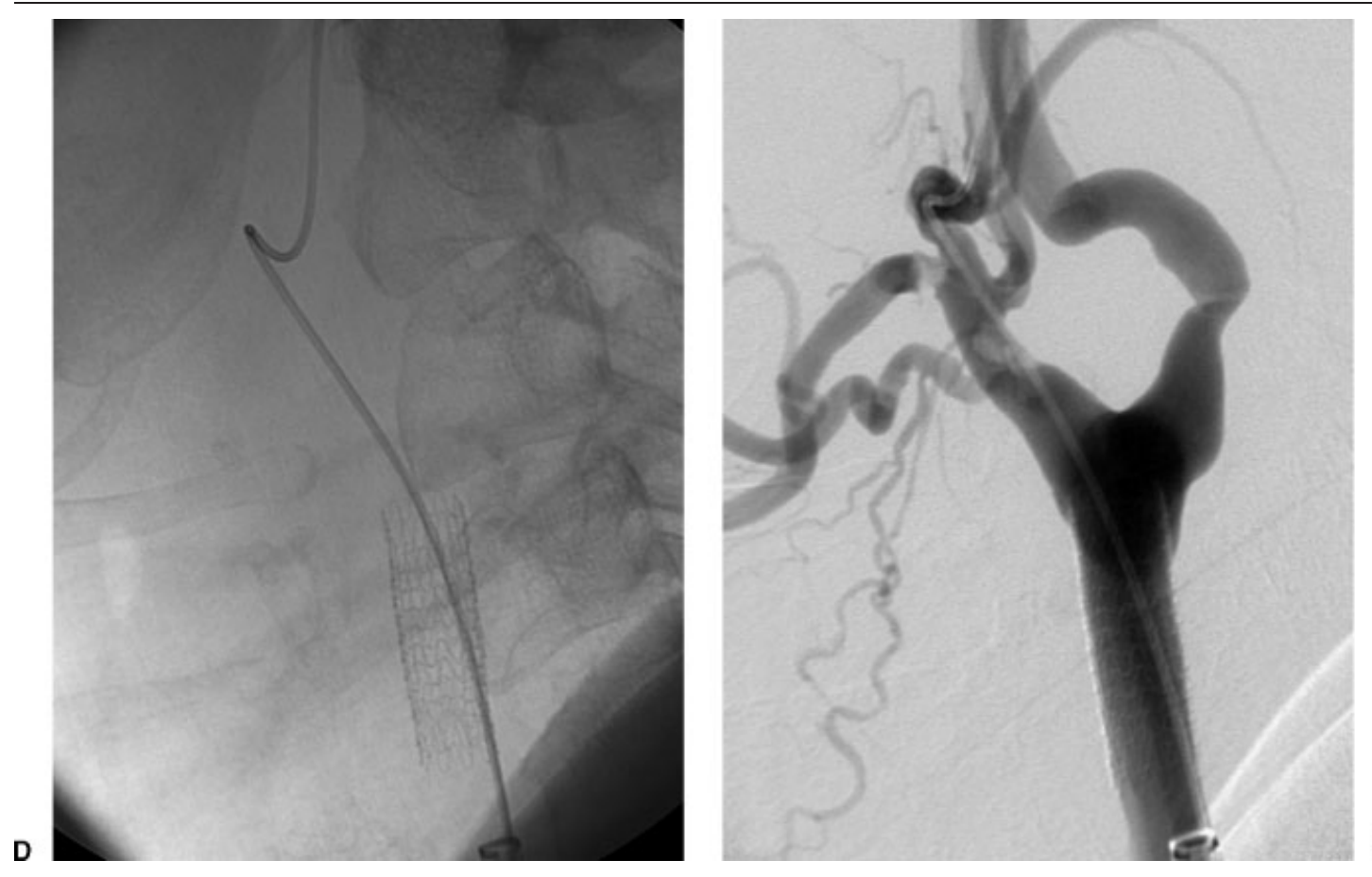

Figure 1 (Continued) (D) Covered stent graft placement resulted in successful pseudoaneurysm exclusion (E).

treatment of laryngeal carcinoma 8 years prior, and he had initially presented to an outside hospital for evaluation of oral bleeding. Carotid angiography performed at that time demonstrated a pseudoaneurysm located in the region of the tumor bed (Figs. 1A,B).

Upon transfer, the patient suffered acute massive hemoptysis, which resulted in hypovolemic shock. The patient was resuscitated with fluids, and his oral and nasal cavities were packed. These clinical findings were consistent with carotid blowout syndrome, and thus emergent angiography was undertaken with therapeutic intent. Through $5 \mathrm{~F}$ left common femoral arterial sheath, a 5F angled Glidecath (Terumo Medical, Somerset, NJ) was guided into the left common carotid artery. Common carotid arteriography revealed partial thrombosis of the previously noted pseudoaneurysm, with persistent filling at its base (Fig. 1C). Endovascular treatment was elected given the clinical hemodynamic significance, and the $5 \mathrm{~F}$ left common femoral artery sheath was upsized to 9F to allow delivery of a covered stent graft. Subsequent treatment with an $8 \times 25 \mathrm{~mm}$ covered self-expanding stent graft (Gore Viabahn Endoprosthesis; W.L. Gore, Flagstaff, AZ) following systemic anticoagulation with $5000 \mathrm{U}$ of heparin resulted in successful exclusion of the pseudoaneurysm and cessation of bleeding (Figs. 1D, E). All devices were removed, and vascular access site hemostasis was obtained using a Perclose device (Abbott Vascular, Redwood City, CA). Following periprocedural antibiotic treatment and an uncomplicated hospital course, the patient was discharged in stable condition on postprocedure day 8 .
One month postprocedure, the patient presented to an outside hospital with recurrent hemorrhage. The treatment course at the outside institution is unknown, and the patient was subsequently lost to follow-up.

\section{DISCUSSION}

Carotid blowout syndrome refers to rupture of the extracranial carotid artery or its major branches. This catastrophic condition has various etiologies, including head and neck malignancy, radiation therapy, and trauma. Diagnosis of carotid artery blowout involves recognition of profuse transoral or transcervical arterial bleeding in a patient with appropriate clinical history. In addition, radiological studies such as computed tomography (CT) and angiography may demonstrate evidence of vascular invasion by tumor or pseudoaneurysm formation. Chaloupka et al. ${ }^{2}$ classified carotid artery blowout by clinical and radiological examination into three categories: (1) threatened blowout, defined as inevitable hemorrhage in the immediate future if no therapeutic action is taken (due to vessel exposure or invasion by tumor); (2) impending blowout, consisting of a short-lived sentinel bleed, generally from a pseudoaneurysm, that resolves spontaneously or with pressure or simple surgical packing; and (3) acute blowout, which is profuse hemorrhage not contained by a pseudoaneurysm, not self-limiting, not well controlled with pressure or surgical packing, and may lead to exsanguination if occlusion of the ruptured vessel is not undertaken. 
Surgical carotid artery ligation is the definitive therapy for carotid artery rupture. However, this management option increases stroke risk and is often challenging in patients with poor tissue health due to head and neck malignancy or neck irradiation. Endovascular therapy for carotid blowout syndrome, as first reported in 1984, involved permanent occlusion of the carotid artery using detachable balloons. ${ }^{3}$ Percutaneous treatments for carotid artery rupture have since evolved to employ coil embolization and have largely supplanted surgical therapy of carotid artery blowout because they are straightforward, efficacious, and safe. Recently, stent-directed endovascular methods have aimed at sparing the carotid artery to reduce neurological morbidity, ${ }^{2,4}$ particularly in patients who cannot tolerate carotid artery sacrifice due to an incomplete circle of Willis. Reported use of carotid-sparing, stentdirected therapies in the setting of impending and acute carotid artery blowout and head and neck malignancy is still relatively limited. In searching the recent literature, we found 19 reported cases of impending and acute carotid blowout syndrome in the setting of head and neck malignancy treated using carotid-sparing, stentdirected approaches with covered stent grafts between 2000 and 2006 (Table 1).

Stent-directed management of acute carotid artery rupture requires the use of covered devices. Covered stent grafts were utilized in all 19 reported cases, as well as in our case. The vascular seal created by the graft material prevents extravasation. According to the literature, covered stent treatment of acute carotid artery rupture represents a relatively efficacious means for initial control of bleeding. Cessation of acute hemorrhage was accomplished in 18 of 19 reported cases, and exclusion of the bleeding pseudoaneurysm was successfully achieved in our patient. The one unsuccessful case was complicated by procedure-related arterial rupture after delivery of a balloon-mounted stent in an already weakened artery. ${ }^{5}$ Polytetrafluoroethylene (PTFE)covered stents were predominantly employed in the reported cases and afforded technical success in our case.

Stent-directed therapy of acute carotid blowout is safe, particularly if using self-expanding devices. Self-expanding stents are advocated over balloonmounted models in the setting of carotid artery blowout $^{6}$ because the former avoids possible arterial rupture as a result of balloon inflation in the weakened carotid artery, as reported by Kwok et al..$^{5}$ Notably, self-expanding stents may also be preferred for technical reasons because these devices can accommodate variable arterial diameters better than balloonmounted devices, especially at the carotid bifurcation. ${ }^{6}$

Recurrent hemorrhage rate following stent graft treatment of carotid artery blowout in the setting of head and neck malignancy is significant, as shown in
Table 1, and is usually related to progression of disease (continued arterial erosion by tumor). Delayed hemorrhage was seen in 5 of 19 reported cases, at mean 24.5 days following initial treatment (given available data). These cases were treated by repeat stenting in two, and vessel sacrifice in two. One case of rebleeding led to patient death. Our patient rebled 32 days postprocedure. Because of the risk of recurrent bleeding, some authors view covered stent therapy of acute carotid blowout as a temporizing measure rather than definitive therapy. ${ }^{6}$ Alternative management options of advanced head and neck malignancy may be considered once initial control of hemorrhage is obtained by stent placement and the patient is stabilized. Arterial bypass and carotid artery sacrifice may be contemplated. Interval repeated bleeding may necessitate carotid artery sacrifice.

Other potential complications of stent-directed treatment of carotid artery blowout include graft infection with septic embolization, endoleak, stent extrusion, and cerebrovascular accident. Graft infection was seen in two cases. One case encountered 4 weeks after treatment was further complicated by stent thrombosis 4 weeks later. ${ }^{7}$ Another case of graft infection resulted in septic embolization and brain abscess formation, as well as vessel thrombosis. ${ }^{8}$ Because the necrotic tumor represents an unsterile field that may result in stent contamination and infection, prophylactic periprocedural antibiotics are recommended. No strict administration guidelines have been established, however. Endoleak may complicate stent graft therapy of carotid artery rupture, particularly if the stent is not properly apposed to the vessel wall during placement. ${ }^{9}$ Balloon angioplasty of the stent may be necessary to ensure tight apposition of the graft to the carotid artery should there be continued extravasation following initial stent delivery. Stent extrusion, or displacement from the vessel, may result in arterial thrombosis and consequent stroke. ${ }^{6}$ Of the five cases of stent thrombosis encountered, two led to ischemic stroke.

Reported survival outcomes were poor in the reported cases due to advanced head and neck malignancy. As such, long-term stent patency is difficult to assess. Nonetheless, patients undergoing stent-directed treatment of carotid blowout syndrome require close clinical follow-up. Interval monitoring with noninvasive imaging, such as duplex sonography, is recommended to assess vessel patency and evaluate for complications such as restenosis, endoleak, and extrusion. Follow-up periods can be individualized on a case-by-case basis. Finally, initiation of antiplatelet therapy with aspirin or clopidogrel can be considered following stent placement to decrease stroke risk, although it may be unsuitable given the significant rehemorrhage risk. As such, antiplatelet medications were not routinely utilized among the reviewed cases. 
Table 1 Reports of Covered Stent Treatment of Impending and Acute Carotid Blowout Syndrome 2000-2006

\begin{tabular}{|c|c|c|c|c|c|c|c|c|}
\hline Author & Case & $\begin{array}{l}\text { Patient } \\
\text { (age/sex) }\end{array}$ & Lesion & Location & $\begin{array}{l}\text { Stent } \\
\text { Material }\end{array}$ & $\begin{array}{l}\text { Technical } \\
\text { Success }\end{array}$ & Complication & Follow-up \\
\hline $\begin{array}{l}\text { Macdonald } \\
\text { et } \mathrm{al}^{7}\end{array}$ & 1 & $\begin{array}{l}1 \\
61 / M\end{array}$ & PseudoA & CCA & PTFE & Yes & Bacteremia & $\begin{array}{l}\text { Died } 5 \text { wk postprocedure } \\
\text { (due to metastatic disease) }\end{array}$ \\
\hline $\begin{array}{l}\text { Kwok } \\
\text { et al }\end{array}$ & 2 & $\begin{array}{l}2 \\
63 / M\end{array}$ & PseudoA & CCA & PTFE & No & $\begin{array}{l}\text { Intraprocedure rupture } \\
\text { (treated with coil } \\
\text { embolization) }\end{array}$ & Died 2 mo postprocedure \\
\hline \multirow[t]{4}{*}{$\begin{array}{l}\text { Warren } \\
\text { et al }^{10}\end{array}$} & 3 & $\begin{array}{l}3 \\
67 / M\end{array}$ & PseudoA & L CCA & \multicolumn{2}{|c|}{ Unspecified Yes } & $\begin{array}{l}\text { Rebleeding ( } 21 \mathrm{~d} \\
\text { postprocedure; treated } \\
\text { with coil embolization) }\end{array}$ & As below \\
\hline & 4 & $\begin{array}{l}3 \\
67 / M\end{array}$ & PseudoA & R CCA & \multicolumn{2}{|c|}{ Unspecified Yes } & $\begin{array}{l}\text { Rebleeding (after several } \\
\text { months, exact time } \\
\text { unspecified) }\end{array}$ & $\begin{array}{l}\text { Died several months } \\
\text { postprocedure } \\
\text { (due to rebleeding) }\end{array}$ \\
\hline & 5 & $\begin{array}{l}4 \\
44 / F\end{array}$ & PseudoA & CCA & PTFE & Yes & $\begin{array}{l}\text { Graft infection (4 wk } \\
\text { postprocedure) } \\
\text { Graft thrombosis } \\
\text { (8 wk postprocedure) }\end{array}$ & Palliative care \\
\hline & 6 & $\begin{array}{l}5 \\
86 / F\end{array}$ & \multicolumn{2}{|c|}{ Unspecified CCA } & \multicolumn{2}{|c|}{ Unspecified Yes } & None & Died 3 mo postprocedure \\
\hline \multirow[t]{2}{*}{$\begin{array}{l}\text { Simental } \\
\text { et al }\end{array}$} & 7 & $\begin{array}{l}6 \\
69 / F\end{array}$ & \multicolumn{2}{|c|}{ Unspecified CCA } & \multicolumn{2}{|c|}{ Unspecified Yes } & $\begin{array}{l}\text { Rebleeding ( } 24 \mathrm{~d} \\
\text { postprocedure; } \\
\text { treated with coil } \\
\text { embolization) }\end{array}$ & $\begin{array}{l}\text { Died } 26 \text { d postprocedure } \\
\text { (due to ischemic stroke) }\end{array}$ \\
\hline & 8 & $\begin{array}{l}7 \\
47 / M\end{array}$ & \multicolumn{2}{|c|}{ Unspecified L CCA } & & Yes & $\begin{array}{l}\text { Graft thrombosis } \\
\text { and extrusion }\end{array}$ & $\begin{array}{l}\text { Died postprocedure } \\
\text { (time unspecified) }\end{array}$ \\
\hline \multirow{3}{*}{$\begin{array}{l}\text { Chaloupka } \\
\text { et al }\end{array}$} & 9 & $\begin{array}{l}8 \\
46 / \mathrm{M}\end{array}$ & PseudoA & ICA & PETP & Yes & None & Stable 1 mo postprocedure \\
\hline & 10 & $\begin{array}{l}9 \\
41 / F\end{array}$ & PseudoA & ECA & PETP & Yes & None & Stable 1 y postprocedure \\
\hline & 11 & $\begin{array}{l}10 \\
54 / M\end{array}$ & PseudoA & ICA & Gortex & Yes & None & Stable 3 mo postprocedure \\
\hline \multirow[t]{2}{*}{$\begin{array}{l}\text { Desuter } \\
\text { et }^{111}\end{array}$} & 12 & $\begin{array}{l}11 \\
\text { Unspecified }\end{array}$ & ICA bleed & ICA & PTFE & Yes & $\begin{array}{l}\text { Postprocedure } \\
\text { thromboembolism } \\
\text { and ischemic stroke }\end{array}$ & Died 7 mo postprocedure \\
\hline & 13 & $\begin{array}{l}12 \\
\text { Unspecified }\end{array}$ & PseudoA & $\mathrm{CB}$ & PTFE & Yes & $\begin{array}{l}\text { Postprocedure } \\
\text { thromboembolism } \\
\text { and ischemic stroke }\end{array}$ & Stable 5 mo postprocedure \\
\hline \multirow[t]{4}{*}{ Kim et al ${ }^{9}$} & 14 & $\begin{array}{l}13 \\
62 / M\end{array}$ & PseudoA & CCA & PTFE & Yes & $\begin{array}{l}\text { Rebleeding (11 d } \\
\text { postprocedure, treated } \\
\text { with repeat stenting) }\end{array}$ & Stable 2 mo postprocedure \\
\hline & 15 & $\begin{array}{l}14 \\
57 / M\end{array}$ & PseudoA & $\mathrm{CB}$ & PTFE & Yes & $\begin{array}{l}\text { Rebleeding (42 days } \\
\text { postprocedure; treated } \\
\text { with repeat stenting) }\end{array}$ & Stable 5 mo postprocedure \\
\hline & 16 & $\begin{array}{l}15 \\
68 / \mathrm{M}\end{array}$ & PseudoA & CCA & PTFE & Yes & None & None \\
\hline & 17 & $\begin{array}{l}16 \\
61 / M\end{array}$ & PseudoA & $\mathrm{CB}$ & PTFE & Yes & None & None \\
\hline $\begin{array}{l}\text { Broomfield } \\
\text { et } \mathrm{al}^{8}\end{array}$ & & $\begin{array}{l}17 \\
50 / F\end{array}$ & PseudoA & ECA & PTFE & Yes & None & Stable 5 mo postprocedure \\
\hline $\begin{array}{l}\text { Chang et } \\
\mathrm{al}^{12}\end{array}$ & 19 & $\begin{array}{l}18 \\
52 / \mathrm{M}\end{array}$ & PseudoA & L CCA & PTFE & Yes & $\begin{array}{l}\text { Graft infection, thrombosis, } \\
\text { extrusion, and brain } \\
\text { abscess formation } \\
\text { (4 mo postprocedure) }\end{array}$ & $\begin{array}{l}\text { Slight R hemiparesis } \\
6 \text { mo postprocedure }\end{array}$ \\
\hline
\end{tabular}

M, male; PseudoA, pseudoaneurysm; CCA, common carotid artery; PTFE, polytetrafluoroethylene; L, left; R, right; F, female; ICA, internal carotid artery; PETP, polyethylene terephthalate; ECA, external carotid artery; CB, carotid bulb. 


\section{CONCLUSION}

Covered stent placement is a quick and effective method for treatment of impending and acute carotid blowout syndrome, with a technical success rate of $\sim 95 \%$ over reported cases. Although this minimally invasive method results in good initial control of bleeding, delayed hemorrhage occurs at a rate of $\sim 25 \%$, with most events arising within 1 month of treatment. This complication, as well as other potential complications of graft infection, endoleak, and stent extrusion, raises significant concern about short-term efficacy and safety of this treatment method. As such, covered stent therapy is at present probably best suited as a temporizing measure rather than a definitive therapeutic option for impending and acute carotid artery rupture.

\section{REFERENCES}

1. Maran AG, Amin M, Wilson HA. Radical neck dissection: a 19-year experience. J Laryngol Otol 1989;103:760-764

2. Chaloupka JC, Putman CM, Citardi MJ, Ross DA, Sasaki CT. Endovascular therapy of carotid blowout syndrome in head and neck surgical patients: diagnostic and managerial considerations. AJNR Am J Neuroradiol 1996;17:843-852

3. Osguthorpe JD, Hungerford GD. Transarterial carotid occlusion: case report and review of the literature. Arch Otolaryngol 1984;110:694-696
4. Lesley WS, Chaloupka JC, Weigele JB, Mangla S, Dogar MA. Preliminary experience with endovascular reconstruction for the management of carotid blowout syndrome. AJNR Am J Neuroradiol 2003;24:975-981

5. Kwok PC, Cheung JY, Tang KW, Wong WK. Re: Endovascular treatment of acute carotid blow-out syndrome. J Vasc Interv Radiol 2001;12:895-896

6. Simental A, Johnson JT, Horowitz M. Delayed complications of endovascular stenting for carotid blowout. Am J Otolaryngol 2003;24:417-419

7. Macdonald S, Gan J, McKay AJ, Edwards RD. Endovascular treatment of acute carotid blow-out syndrome. J Vasc Interv Radiol 2000;11:1184-1188

8. Broomfield SJ, Bruce IA, Luff DA, Birzgalis AR, Ashleigh RJ. Endovascular management of the carotid blowout syndrome. J Laryngol Otol 2006;120:694-697

9. Kim HS, Lee DH, Kim HJ, et al. Life-threatening common carotid artery blowout: rescue treatment with a newly designed self-expanding covered nitinol stent. Br J Radiol 2006;79:226-231

10. Warren FM, Cohen JI, Nesbit GM, Barnwell SL, Wax MK, Andersen PE. Management of carotid "blowout" with endovascular stent grafts. Laryngoscope 2002;112:428-433

11. Desuter G, Hammer F, Gardiner Q, et al. Carotid stenting for impending carotid blowout: suitable supportive care for head and neck cancer patients? Palliat Med 2005;19:427-429

12. Chang FC, Lirng JF, Tai SK, Luo CB, Teng MM, Chang CY. Brain abscess formation: a delayed complication of carotid blowout syndrome treated by self-expandable stentgraft. AJNR Am J Neuroradiol 2006;27:1543-1545 